\title{
PEMODELAN DATA KEMISKINAN PROVINSI SUMATERA BARAT MENGGUNAKAN REGRESI SPASIAL
}

\author{
Fitri Mudia Sari ${ }^{1}$ \\ Hendry Frananda Nasution ${ }^{2}$ \\ Pardomuan Robinson Sihombing ${ }^{3 *}$ \\ ${ }^{1}$ Jurusan Statistika, Universitas Negeri Padang, Indonesia \\ ${ }^{2}$ Jurusan Geografi, Universitas Negeri Padang, Indonesia \\ ${ }^{3}$ Badan Pusat Statistik (BPS), Jakarta, Indonesia
}

robinson@bp.go.id ${ }^{3 *}$

\begin{abstract}
ABSTRAK
Kemiskinan merupakan suatu masalah yang menjadi perhatian di setiap negara. Permasalahan kemiskinan di suatu daerah tidak hanya dipengaruhi oleh faktor-faktor kemiskinan di daerah tersebut, tetapi juga dapat dipengaruhi oleh kemiskinan di daerah lain sehingga kasus kemiskinan dapat dikaji dengan analisis spasial. Model spasial yang dapat digunakan untuk permasalahan ini adalah regresi spasial, diantaranya yaitu model autoregresif spasial dan model galat spasial. Tujuan dari penelitian ini adalah menentukan faktor-faktor yang mempengaruhi kemiskinan di Provinsi Sumatera Barat dengan menggunakan regresi spasial. Hasil penelitian menunjukkan model terbaik adalah model SAR dan faktor-faktor yang mempengaruhi yaitu persentase rumah tangga penduduk dengan sanitasi layak dan persentase penduduk dengan air bersih dan kemiskinan kabupaten/kota di sekitarnya.
\end{abstract}

Keyword: kemiskinan, model autoregresif spasial, model galat spasial, regresi spasial

Diterbitkan Oleh:

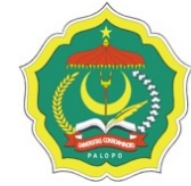

Fakultas Sains

Program Studi Matematika

Universitas Cokroaminoto Palopo

Copyright (C) 2021 The Author (s)

This article is licensed under CC BY 4.0 License

\section{(cc) $\mathrm{BY}$}




\section{PEMODELAN DATA KEMISKINAN PROVINSI SUMATERA BARAT MENGGUNAKAN REGRESI SPASIAL}

\section{Pendahuluan}

Kemiskinan merupakan suatu masalah yang menjadi perhatian di setiap negara. Karena pembangunan di suatu negara pada dasarnya bertujuan untuk menciptakan kemakmuran dan mengurangi kemiskinan. Oleh karena itu pemerintah di setiap negara melakukan berbagai macam cara untuk mengurangi kemiskinan. Indonesia merupakan negara yang masih memiliki persentase tingkat kemiskinan yang cukup tinggi. Faktor penyebab kemiskinan di Indonesia sangat beragam. Hakim \& Zuber (dalam Djuraidah \& Wigena, 2012) menyatakan bahwa lokasi tempat tinggal, akses ke teknologi, dan ketersediaan sumber alam berpengaruh terhadap kemiskinan. Permasalahan kemiskinan di suatu daerah tidak hanya dipengaruhi oleh faktorfaktor kemiskinan di daerah tersebut, tetapi juga dapat dipengaruhi oleh kemiskinan di daerah lain sehingga kasus kemiskinan dapat dikaji dengan analisis spasial (Alvitiani, Yasin, dan Mukid, 2019). Hal ini sejalan dengan hukum geografi yang dikemukakan Tobler (Tobler 's first law of geography) dalam Schabenberger dan Gotway (2005), yang menyatakan "everything is related to everything else, but near things are more related than distant things". Segala sesuatu saling berhubungan satu dengan yang lainnya, tetapi sesuatu yang lebih dekat akan lebih berpengaruh daripada sesuatu yang jauh. Pada umumnya efek atau pengaruh spasial ini cukup lazim terjadi antara satu wilayah dengan wilayah lainnya, dan terjadi pada setiap data cross section.

Analisis yang dapat digunakan untuk melihat faktor-faktor yang berpengaruh terhadap kemiskinan adalah analisis regresi. Analisis regresi menghasilkan suatu modle persamaan yang dapat digunakan untuk memprediksi peubah respon jika diketahui peubah prediktornya. Dalam regresi linier yang menggunakan metode OLS (Ordinary Least Square) ada asumsi-asumsi yang harus dipenuhi. Salah satunya adalah antar pengamatan harus saling bebas (nonautokorelasi. Sementara dalam menganalisis kemiskinan suatu daerah aspek lokasi pada suatu pengamatan sangat diperlukan, karena kondisi kemiskinan suatu wilayah sangat mungkin dipengaruhi oleh lokasi pengamatan atau kondisi geografis wilayah tersebut, termasuk posisinya terhadap wilayah lain di sekitarnya (Djuraidah \& Wigena, 2012). Sehingga kondisi non-autokorelasi akan sangat mungkin untuk dilanggar.

Model regresi spasial dikembangkan oleh Anselin pada tahun 1988 menggunakan data control-section, model ini disebut dengan General Spatial Model. Dalam membuat model 
regresi spasial terdapat matriks pembobot yang berfungsi untuk melihat hubungan antara suatu lokasi dengan lokasi lain. Ada beberapa pendekatan yang digunakan dalam matriks pembobot, salah satunya dengan pendekatan area berupa ketetanggaan antar wilayah (LeSage 1999).

Penelitian ini bertujuan untuk menentukan faktor-faktor yang berpengaruh terhadap kemiskinan di Provinsi Sumatera Barat dengan menggunakan model regresi spasial yaitu model autoregresif spasial (Spatial Autoregressive Model, SAR) dan model galat spasial (Spatial Error Model, SEM).

\section{Tinjauan Pustaka}

\subsection{Regresi Linear}

Persamaan regresi linear yang biasa didefinisikan dengan menggunakan metode pendugaan parameter Ordinary Least Square (OLS), secara umum dapat dituliskan sebagai berikut.

$y_{i}=\beta_{0}+\sum_{j=1}^{p} \beta_{p} X_{i j}+\varepsilon_{i}$

$i=1,2, \ldots, n ; j=1, \ldots, p$

dengan:

$y_{i}:$ peubah respon

$\beta_{0}:$ konstanta

$X_{i j}$ : nilai peubah bebas ke-j pada pengamatan ke- $i$

$\beta_{p}$ : nilai koefisien peubah penjelas $X_{i}$

$\varepsilon_{i}$ : galat acak pengamatan ke- $i$

Vektor galat $\varepsilon$ diasumsikan menyebar $\mathrm{N}\left(\mathbf{0}, \sigma^{2} \boldsymbol{I}\right)$. Dalam notasi matriks, persamaan regresi di atas dapat dituliskan sebagai berikut.

$\boldsymbol{y}=\boldsymbol{X} \boldsymbol{\beta}+\varepsilon$,

Pendugaan $\boldsymbol{\beta}$ dilakukan dengan menggunakan OLS, yaitu dengan meminimumkan jumlah kuadrat galat $\boldsymbol{\varepsilon}^{\prime} \boldsymbol{\varepsilon}$. Nilai $\boldsymbol{\beta}$ diduga dengan rumus:

$\widehat{\boldsymbol{\beta}}=\left(\boldsymbol{X}^{\prime} \boldsymbol{X}\right)^{-1} \boldsymbol{X}^{\prime} \boldsymbol{Y}$

dimana:

$\widehat{\boldsymbol{\beta}}=\left(\hat{\beta}_{0}, \hat{\beta}_{1}, \ldots, \hat{\beta}_{p}\right)^{\prime}$ : vektor koefisien regresi

$X$ : matriks peubah penjelas berukuran

$$
n \times(p+1)
$$

dengan kolom pertama bernilai 1 untuk konstanta 
$\boldsymbol{Y}$ : vektor peubah respon

\subsection{Model umum Regresi Spasial (General Spatial Model, GSM)}

Bentuk persamaan model umum regresi spasial adalah sebagai berikut:

$\boldsymbol{y}=\rho \boldsymbol{W} \boldsymbol{y}+\boldsymbol{X} \boldsymbol{\beta}+\boldsymbol{u}$

(4)

$\boldsymbol{u}=\lambda \boldsymbol{W} \boldsymbol{u}+\boldsymbol{\varepsilon}$

$\boldsymbol{\varepsilon} \sim N\left(0, \sigma^{2} \boldsymbol{I}\right)$

(6)

dengan:

$\boldsymbol{y} \quad$ : vektor peubah respon berukuran $n \times 1$

$\boldsymbol{X} \quad$ : matriks peubah penjelas berukuran $p \times(n+1)$

$\boldsymbol{\beta} \quad$ : vektor koefisien parameter regresi yang berukuran $p \times 1$

$\rho \quad$ : koefisien autokorelasi spasial pada peubah respon yang bernilai $|\rho|<1$

$\lambda \quad$ : koefisien autokorelasi spasial pada galat yang bernilai $|\lambda|<1$

$\boldsymbol{u} \quad$ : vektor galat berukuran $n \times 1$

W : matriks pembobot spasial yang berukuran $n \times n$

$\boldsymbol{\varepsilon} \quad$ : galat acak yang diasumsikan menyebar normal

Pendugaan parameter pada model GSM diperoleh dengan metode penduga kemungkinan maksimum (Anselin 1988). Persamaan (4) dapat dinyatakan sebagai berikut:

$y-\rho W y=X \beta+u$ atau

$(I-\rho W) y=X \beta+u$

Persamaan (5) dapat dinyatakan dalam bentuk:

$(\boldsymbol{I}-\lambda \boldsymbol{W}) \boldsymbol{u}=\boldsymbol{\varepsilon}$ atau

$\boldsymbol{u}=(\boldsymbol{I}-\lambda \boldsymbol{W})^{-\mathbf{1}} \boldsymbol{\varepsilon}$

Substitusikan persamaan (8) ke persamaan (7), diperoleh:

$$
\begin{aligned}
& (I-\rho W) \boldsymbol{y}=\boldsymbol{X} \boldsymbol{\beta}+(I-\lambda \boldsymbol{W})^{-\mathbf{1}} \boldsymbol{\varepsilon} \\
& (I-\lambda \boldsymbol{W})^{-\mathbf{1}} \boldsymbol{\varepsilon}=(I-\rho \boldsymbol{W}) \boldsymbol{y}-\boldsymbol{X} \boldsymbol{\beta}
\end{aligned}
$$

Jika semua ruas dikalikan dengan $(\boldsymbol{I}-\lambda \boldsymbol{W})$, maka:

$\boldsymbol{\varepsilon}=(\boldsymbol{I}-\rho \boldsymbol{W})(\boldsymbol{I}-\lambda \boldsymbol{W}) \boldsymbol{y}-\boldsymbol{X} \boldsymbol{\beta}$

Nilai fungsi likelihood dari galat $\boldsymbol{\varepsilon}$ adalah:

$$
L\left(\sigma^{2} ; \boldsymbol{\varepsilon}\right)=c(\boldsymbol{\varepsilon})|\boldsymbol{V}|^{-\frac{1}{2}} \exp \left[-\frac{1}{2} \boldsymbol{\varepsilon}^{T} \boldsymbol{V}^{-1} \boldsymbol{\varepsilon}\right]
$$


dengan $\boldsymbol{V}$ adalah matriks ragam-koragam dari $\boldsymbol{\varepsilon}$ yang bernilai $\boldsymbol{V}=\sigma^{2} \boldsymbol{I}$. Determinan matriks $\boldsymbol{V}$ adalah $\sigma^{2 n}$ dan kebalikan dari matriks ragam-koragam adalah $\boldsymbol{V}^{-\mathbf{1}}=1 /\left(\sigma^{2} \boldsymbol{I}\right)$. Dengan mensubstitusikan nilai $\boldsymbol{V}$ dan $\left|\boldsymbol{V}^{-\mathbf{1}}\right|$ pada persamaan (6) maka diperoleh:

$L\left(\sigma^{2} ; \boldsymbol{\varepsilon}\right)=c(\boldsymbol{\varepsilon}) \sigma^{2 n^{-\frac{1}{2}}} \exp \left[-\frac{1}{2 \sigma^{2 n}} \boldsymbol{\varepsilon}^{T} \boldsymbol{\varepsilon}\right]$

Dari hubungan $\boldsymbol{\varepsilon}$ dan $\boldsymbol{y}$ dari persamaan (11), diperoleh nilai Jacobian:

$$
J=\left|\frac{\partial \varepsilon}{\partial y}\right|=|\boldsymbol{I}-\lambda \boldsymbol{W}||\boldsymbol{I}-\rho \boldsymbol{W}|
$$

Dengan mensubstitusikan persamaan (5) ke dalam persamaan (7) diperoleh fungsi likelihood untuk $\boldsymbol{y}$ yaitu:

$$
\begin{aligned}
& L\left(\rho, \lambda, \sigma^{2}, \boldsymbol{\beta} ; \boldsymbol{y}\right)=c(\boldsymbol{y}) \sigma^{2 n^{-\frac{1}{2}}}|\boldsymbol{I}-\lambda \boldsymbol{W} \| \boldsymbol{I}-\rho \boldsymbol{W}| \exp \left[-\frac{1}{2 \sigma^{2 n}}\{(\boldsymbol{I}-\rho \boldsymbol{W})[(\boldsymbol{I}-\rho \boldsymbol{W}) \boldsymbol{y}-\right. \\
& \left.\boldsymbol{X} \boldsymbol{\beta}]\}^{T}\{(\boldsymbol{I}-\rho \boldsymbol{W})[(\boldsymbol{I}-\rho \boldsymbol{W}) \boldsymbol{y}-\boldsymbol{X} \boldsymbol{\beta}]\}\right]
\end{aligned}
$$

dan fungsi log-likelihood persamaan (12) adalah sebagai berikut:

$$
\begin{gathered}
l\left(\rho, \lambda, \sigma^{2}, \boldsymbol{\beta} ; \boldsymbol{y}\right)=c(\boldsymbol{y})-\frac{n}{2} \ln \left(\sigma^{2}\right)+\ln |\boldsymbol{I}-\lambda \boldsymbol{W}|+\ln |\boldsymbol{I}-\rho \boldsymbol{W}|-\frac{1}{2 \sigma^{2}}\{(\boldsymbol{I}-\rho \boldsymbol{W})[(\boldsymbol{I}- \\
\rho \boldsymbol{W}) \boldsymbol{y}-\boldsymbol{X} \boldsymbol{\beta}]\}^{T}\{(\boldsymbol{I}-\rho \boldsymbol{W})[(\boldsymbol{I}-\rho \boldsymbol{W}) \boldsymbol{y}-\boldsymbol{X} \boldsymbol{\beta}]\}
\end{gathered}
$$

Misalkan kuadrat matriks pembobot $(\boldsymbol{I}-\rho \boldsymbol{W})^{T}(\boldsymbol{I}-\rho \boldsymbol{W})$ dinotasikan sebagai $\boldsymbol{\Omega}$ dan penduga $\boldsymbol{\beta}$ diperoleh dengan memaksimalkan fungsi log-likelihood pada persamaan (13), akan diperoleh:

$$
\widehat{\boldsymbol{\beta}}=\left(\boldsymbol{X}^{\prime} \boldsymbol{\Omega} \boldsymbol{X}\right)^{-1} \boldsymbol{X}^{\prime} \boldsymbol{\Omega}(\boldsymbol{I}-\lambda \boldsymbol{W}) \boldsymbol{y}
$$

\subsection{Model Autoregresif Spasial (Spatial Autoregressive Model, SAR)}

Jika $\rho \neq 0$ dan $\lambda=0$, maka persamaan (4) menjadi:

$$
\begin{gathered}
\boldsymbol{y}=\rho \boldsymbol{W} \boldsymbol{y}+\boldsymbol{X} \boldsymbol{\beta}+\boldsymbol{\varepsilon} \\
\boldsymbol{\varepsilon} \sim N\left(0, \sigma^{2} \boldsymbol{I}\right)
\end{gathered}
$$

Model autoregresif spasial adalah model yang peubah responnya berkorelasi spasial. Fungsi log-likelihood model SAR diperoleh dari persamaan (10) dengan menggantikan nilai $\lambda=0$ maka akan diperoleh:

$$
\begin{aligned}
l= & L\left(\rho, \sigma^{2}, \boldsymbol{\beta} ; \boldsymbol{y}\right)=\ln \left(\frac{|\boldsymbol{I}-\rho \boldsymbol{W}|}{(2 \pi)^{n / 2} \sigma^{n}} \exp \left[-\frac{(y-\rho \boldsymbol{W}-\boldsymbol{X} \boldsymbol{\beta})^{T}(y-\rho \boldsymbol{W}-\boldsymbol{X} \boldsymbol{\beta})}{2 \sigma^{2}}\right]\right)=-\frac{n}{2} \ln (2 \pi)-\frac{n}{2} \ln \sigma^{2}+ \\
& \ln |\boldsymbol{I}-\rho \boldsymbol{W}|-\frac{(y-\rho \boldsymbol{W}-\boldsymbol{X} \boldsymbol{\beta})^{T}(y-\rho \boldsymbol{W}-\boldsymbol{X} \boldsymbol{\beta})}{2 \sigma^{2}}
\end{aligned}
$$

Pendugaan untuk $\sigma^{2}, \boldsymbol{\beta}$, dan $\rho$ diperoleh dengan memaksimumkan fungsi log-likelihood pada persamaan (11), yaitu: 
$\hat{\sigma}^{2}=\frac{(y-\rho \boldsymbol{W}-\boldsymbol{X} \boldsymbol{\beta})^{T}(y-\rho \boldsymbol{W}-\boldsymbol{X} \boldsymbol{\beta})}{n}$

Persamaan (12) dapat ditulis sebagai:

$$
\hat{\sigma}^{2}=\frac{\sum\left(y_{i}-\hat{y}_{i}\right)^{2}}{n}=\frac{S S_{E}}{n}
$$

dengan $y_{i}$ : peubah respon pada lokasi ke- $i$

$\hat{y}_{i}$ : nilai penduga peubah respon lokasi ke- $i$

$n$ : banyak pengamatan

$S S_{E}:$ jumlah kuadrat galat

Penduga untuk $\boldsymbol{\beta}$ adalah:

$$
\widehat{\beta}=\left(X^{T} X\right)^{-1} X^{T} Y-\left(X^{T} X\right)^{-1} \hat{\rho} W y
$$

dan penduga untuk $\rho$ adalah:

$$
\hat{\rho}=\left(\boldsymbol{y}^{T} W^{T} W y\right)^{-1} y^{T} W^{T} y
$$

\subsection{Model Galat Spasial (Spatial Error Model, SEM)}

Jika $\rho=0$ dan $\lambda \neq 0$, maka persamaan (4) menjadi:

$$
\begin{aligned}
\boldsymbol{y}= & \boldsymbol{X} \boldsymbol{\beta}+\boldsymbol{u} \\
& \boldsymbol{u}=\lambda \boldsymbol{W} \boldsymbol{u}+\boldsymbol{\varepsilon} \\
& \boldsymbol{\varepsilon} \sim N\left(0, \sigma^{2} \boldsymbol{I}\right)
\end{aligned}
$$

Model galat spasial adalah model regresi liniear yang terdapat korelasi spasial pada peubah galatnya. Fungsi log-likelihood model SEM diperoleh dari persamaan (9) dengan menggantikan nilai $\rho=0$ akan diperoleh:

$$
\begin{aligned}
& l=L\left(\rho, \lambda, \sigma^{2}, \boldsymbol{\beta} ; \boldsymbol{y}\right)=\ln \left(\frac{|\boldsymbol{I}-\lambda \boldsymbol{W}|}{(2 \pi)^{n / 2} \sigma^{n}} \exp \left[-\frac{(\boldsymbol{y}-\boldsymbol{X} \boldsymbol{\beta})^{T}(\boldsymbol{I}-\lambda \boldsymbol{W})^{T}(\boldsymbol{I}-\lambda \boldsymbol{W})(\boldsymbol{y}-\boldsymbol{X} \boldsymbol{\beta})}{2 \sigma^{2}}\right]\right)=-\frac{n}{2} \ln (2 \pi)- \\
& \frac{n}{2} \ln \sigma^{2}+\ln |\boldsymbol{I}-\lambda \boldsymbol{W}|-\frac{(\boldsymbol{y}-\boldsymbol{X} \boldsymbol{\beta})^{T}(\boldsymbol{I}-\lambda \boldsymbol{W})^{T}(\boldsymbol{I}-\lambda \boldsymbol{W})(\boldsymbol{y}-\boldsymbol{X} \boldsymbol{\beta})}{2 \sigma^{2}}
\end{aligned}
$$

Pendugaan untuk $\sigma^{2}, \boldsymbol{\beta}$, dan $\lambda$ diperoleh dengan memaksimumkan fungsi log-likelihood pada persamaan (14), yaitu:

$$
\begin{aligned}
& \hat{\sigma}^{2}=\frac{(\boldsymbol{I}-\lambda \boldsymbol{W})(\boldsymbol{y}-\boldsymbol{X} \widehat{\boldsymbol{\beta}})^{T}(\boldsymbol{I}-\lambda \boldsymbol{W})(\boldsymbol{y}-\boldsymbol{X} \widehat{\boldsymbol{\beta}})}{n} \\
& \widehat{\boldsymbol{\beta}}=\left[(\boldsymbol{X}-\hat{\lambda} \boldsymbol{W} \boldsymbol{X})^{\boldsymbol{T}}(\boldsymbol{X}-\hat{\lambda} \boldsymbol{W} \boldsymbol{X})\right]^{-\mathbf{1}}(\boldsymbol{X}-\hat{\lambda} \boldsymbol{W} \boldsymbol{X})^{\boldsymbol{T}}(\boldsymbol{y}-\hat{\lambda} \boldsymbol{W} \boldsymbol{X})
\end{aligned}
$$

Untuk menduga parameter $\lambda$ diperlukan suatu iterasi numerik yang memaksimumkan fungsi log-likelihood tersebut. 


\subsection{Matriks Pembobot Spasial}

Matriks pembobot spasial merupakan matriks yang menggambarkan hubungan kedekatan antar wilayah pengamatan yang berukuran $n \times n$. Pada penelitian ini matriks pembobot spasial yang digunakan adalah matriks pembobot Queen. Matriks pembobot spasial Queen mendifinisikan $w_{i j}=1$ untuk wilayah yang bersebelahan atau titik sudutnya bertemu dengan wilayah yang menjadi perhatian, sedangkan $w_{i j}=0$ untuk wilayah yang tidak bersentuhan sisi maupun sudutnya. Matriks pembobot spasial merupakan matriks simetris dan diagonal utama selalu bernilai nol (Lee \& Wong 2001).

\section{Metode Penelitian}

\subsection{Data}

Data yang digunakan dalam penelitian ini adalah data sekunder yang diperoleh dari buku Sumatera Barat dalam angka tahun 2020 yang meliputi 19 kabupaten/kota. Peubah penelitian yang digunakan adalah sebagai berikut:

Y : Persentase penduduk miskin di Sumatera Barat tahun 2019

$\mathrm{X}_{1}$ : Persentase rumah tangga dengan sanitasi layak

$\mathrm{X}_{2}$ : Persentase penduduk dengan air bersih

$\mathrm{X}_{3}$ : Kepadatan penduduk per $\mathrm{km}^{2}$

\subsection{Langkah-Langkah Analisis}

Langkah-langkah yang dilakukan dalam penelitian ini adalah:

1. Melakukan pendugaan dan pengujian parameter model regresi klasik.

2. Menguji efek spasial yaitu uji dependensi spasial dilakukan dengan uji Lagrange Multiplier (LM).

3. Menduga parameter untuk persamaan model regresi spasial dengan metode penduga kemungkinan maksimum.

4. Memeriksa asumsi pada model regresi yang dihasilkan yaitu kenormalan galat diuji secara formal dengan uji Anderson-Darling. Kehomogenan ragam galat diuji menggunakan uji Breusch-Pagan. Kebebasan galat diuji menggunakan uji moran indeks.

5. Memilih model terbaik antara model regresi biasa dengan model regresi spasial dengan menggunakan nilai AIC.

6. Menentukan faktor-faktor yang mempengaruhi kemiskinan di Sumatera Barat berdasarkan model terbaik. 


\section{HASIL DAN PEMBAHASAN}

\subsection{Deskriptif Statistik}

Tabel 1 menyajikan deskriptif statistik dari peubah-peubah yang digunakan dalam penelitian ini. Rata-rata persentase jumlah penduduk miskin di kabupaten/kota yang terdapat di Sumatera Barat adalah 6,38\%. Rata-rata persentase rumah tangga dengan sanitasi layak adalah $65,76 \%$. Rata-rata rata-rata persentase penduduk dengan air bersih adalah 81,21\%. Dan kepadatan penduduk adalah 769,75 per $\mathrm{km}^{2}$.

Tabel 1. Deksriptif Statistik dari Peubah-Peubah yang Digunakan dalam Penelitian

\begin{tabular}{lllll}
\hline & $\mathrm{N}$ & Minimum & Maksimum & Rataan \\
\hline $\mathrm{Y}$ & 19 & 2,17 & 14,43 & 6,38 \\
$\mathrm{X}_{1}$ & 19 & 40,24 & 86,32 & 65,76 \\
$\mathrm{X}_{2}$ & 19 & 51,99 & 98,9 & 81,21 \\
$\mathrm{X}_{3}$ & 19 & 15,31 & 5181,39 & 769,75 \\
\hline
\end{tabular}

\subsection{Model Regresi Klasik}

Tabel 2 menunjukkan hasil taksiran parameter dari model regresi klasik.

Tabel 2. Taksiran Parameter Model Regresi Klasik

\begin{tabular}{lllll}
\hline & Taksiran parameter & Standar eror & Nilai t & Nilai $\mathrm{p}$ \\
\hline $\mathrm{c}$ & 19,550 & 3,0457 & 6,419 & $1,16 \mathrm{e}-05 * *$ \\
$\mathrm{X}_{1}$ & $-0,0717$ & 0,0364 & $-1,96$ & $0,0677^{*}$ \\
$\mathrm{X}_{2}$ & $-0,1094$ & 0,0401 & $-2,73$ & $0,0155^{* *}$ \\
$\mathrm{X}_{3}$ & 0,0006 & 0,0004 & 1,27 & 0,2220 \\
AIC $=80,47$ & $R^{2}=60,27 \%$ & $\mathrm{~F}=7,585$ & $\mathrm{P}=0,025$ \\
\hline
\end{tabular}

Berdasarkan hasil pengujian secara serentak pada alpha 5\% diperoleh nilai-p untuk uji F sebesar 0,025, sehingga keputusan dari pengujian parameter secara simultan menyatakan bahwa belum cukup bukti untuk menerima $H_{0}$, yang artinya bahwa paling tidak ada satu peubah prediktor yang berpengaruh signifikan terhadap peubah respon. Pada alpha 5\%, peubah $\mathrm{X}_{2}$ (persentase RT dengan sanitasi layak) berpengaruh signifikan terhadap peubah respon (persentase penduduk miskin), sedangkan peubah $\mathrm{X}_{2}$ (persentase penduduk dengan air bersih) berpengaruh signifikan terhadap peubah respon pada alpha $10 \%$, sementara peubah $\mathrm{X}_{3}$ (kepadatan penduduk) tidak berpengaruh signifikan terhadap perubahan peubah respon. Persamaan regresi yang terbentuk memberikan nilai $R^{2}$ sebesar $60,27 \%$ yang berarti model dapat menjelaskan keragaman peubah respon sebesar $60,27 \%$ sedangkan sisanya sebesar $30,73 \%$ dijelaskan oleh peubah lain diluar model.

\subsection{Pengujian Efek Spasial}

Pengujian ini bertujuan untuk mengetahui adanya ketergantungan spasial pada model 
regresi yang berpengaruh terhadap Persentase Penduduk Miskin di Sumatera Barat. Uji Lagrange Multiplier (LM) digunakan untuk mendeteksi otokorelasi spasial secara pada peubah respon dan galat. Hasil yang diperoleh dari uji LM akan dijadikan dasar dalam pembentukan model regresi spasial.

Tabel 3. Hasil Uji Ketergantungan Spasial dengan Uji LM

\begin{tabular}{llll}
\hline Model & Nilai LM & Nilai $\mathrm{p}$ & Kesimpulan \\
\hline SAR & 5,6317 & 0,0176 & Tolak $\mathrm{H}_{0}$ \\
SEM & 0,0363 & 0,8489 & Terima $\mathrm{H}_{0}$ \\
\hline
\end{tabular}

Berdasarkan Tabel 3 didapatkan nilai p pada model spasial lag yang lebih kecil dari $\alpha=0,05$ sehingga disimpulkan tolak $\mathrm{H}_{0}$ artinya terdapat ketergantungan spasial lag sehingga dapat dilanjutkan pada pembentukkan model SAR. Uji LM pada model galat spasial memberikan nilai-p yang lebih besar dari $\alpha=0,05$ yang menunjukkan bahwa tidak terdapat galat spasial sehingga tidak dapat dilanjutkan pada pembentukkan model galat spasial.

\subsection{Model Autoregresif Spasial}

Pemodelan menggunakan model autoregresif spasial (SAR) memberikan pubah prediktor yang berpengaruh signifikan pada $\alpha=0,05$ terhadap peubah respon yaitu peubah $\mathrm{X}_{2}$ (persentase RT dengan sanitasi layak) dan peubah $\mathrm{X}_{2}$ (persentase penduduk dengan air bersih), sementara peubah $\mathrm{X}_{3}$ (kepadatan penduduk) tidak berpengaruh signifikan terhadap perubahan peubah respon. Tabel 4 menunjukkan taksiran parameter pada model SAR.

Tabel 4. Taksiran Parameter Model Autoregresif Spasial (SAR)

\begin{tabular}{llll}
\hline & Taksiran parameter & Nilai $\mathrm{p}$ & Kesimpulan \\
\hline $\mathrm{c}$ & 20,6374 & 0,0000 & Signifikan \\
$\mathrm{X} 1$ & $-0,0611$ & 0,0057 & Signifikan \\
$\mathrm{X} 2$ & $-0,0752$ & 0,0034 & Signifikan \\
$\mathrm{X} 3$ & 0,0004 & 0,1653 & Tidak signifikan \\
$\rho$ & $-0,7192$ & 0,0003 & Signifikan \\
$\mathrm{AIC}=69,66$ & & \\
\hline
\end{tabular}

Model SAR yang terbentuk adalah:

$$
\hat{y}=20,6374-0,7193 W y-0,0611 X_{1}-0,0752 X_{2}+0,0004 X_{3}
$$

Nilai dugaan parameter $(\widehat{\boldsymbol{\beta}})$ yang bernilai negatif menunjukkan bahwa jika nilai peubah penjelas tersebut meningkat, maka nilai peubah respon akan menurun. Peningkatan persentase rumah tangga yang memiliki sanitasi layak $\left(\mathrm{X}_{2}\right)$ akan menurunkan tingkat kemiskinan di Sumatera Barat. Begitu juga dengan peningkatan persentase penduduk dengan air bersih $\left(\mathrm{X}_{2}\right)$ akan menurunkan tingkat kemiskinan. Koefisien $\rho$ yang nyata menunjukkan bahwa jika suatu wilayah yang bertetangga dengan wilayah lain, maka pengaruh dari masing-masing wilayah 
yang mengelilinginya dapat diukur sebesar -0,7193 dikali dengan rata-rata persentase penduduk miskin di wilayah sekitarnya.

Pengujian asumsi pada model SAR adalah uji homoskedastisitas, kenormalan, dan kebebasan dari galat model. Hasil pengujian pada tabel 5 menunjukkan ketiga asumsi tersebut terpenuhi.

Tabel 5. Pengujian Asumsi Galat pada Model SAR

\begin{tabular}{llll}
\hline Asumsi & Kenormalan & Kehomogenan & Kebebasan \\
\hline Uji & AD & BP & Moran's \\
Nilai uji & 0,3718 & 53,453 & 0,0056 \\
Nilai p & 0,3849 & 0,1482 & 0,3466 \\
Kesimpulan & Terima $\mathrm{H}_{0}$ & Terima $\mathrm{H}_{0}$ & Terima $\mathrm{H}_{0}$ \\
\hline
\end{tabular}

\subsection{Pemilihan Model Terbaik}

Kriteria yang digunakan untuk memilih model adalah nilai AIC, nilai $\mathrm{R}^{2}$ tidak bisa dijadikan pembanding antara model OLS dan model regresi spasial. Hal ini disebabkan karena nilai $\mathrm{R}^{2}$ pada regresi spasial adalah pseudo $\mathrm{R}$ sehingga tidak sebanding dengan $\mathrm{R}^{2}$ pada model OLS (Medina \& Solymosi, 2019). Model dikatakan baik jika memiliki nilai AIC yang lebih kecil. Dari hasil analisis regresi klasik dan regresi spasial pada Tabel 2 dan Tabel 4 diperoleh bahwa nilai AIC untuk model SAR lebih kecil dibandingkan model OLS, sehingga model yang dipilih untuk menganalisis faktor-faktor yang berpengaruh terhadap perubahan persentase penduduk miskin di Sumatera Barat adalah model SAR dengan peubah yang berpengaruh signifikan adalah persentase rumah tangga penduduk dengan sanitasi layak $\left(\mathrm{X}_{1}\right)$ dan persentase penduduk dengan air bersih $\left(\mathrm{X}_{2}\right)$.

\section{KESIMPULAN}

Berdasarkan nilai AIC terendah, maka dapat disimpulkan bahwa model regresi SAR lebih baik dibandingkan model OLS dalam menentukan faktor-faktor yang berpengaruh terhadap kemiskinan di Provinsi Sumatera Barat. Faktor-faktor yang berpengaruh secara signifikan terhadap persentase kemiskinan berdasarkan model SAR adalah persentase rumah tangga penduduk dengan sanitasi layak dan persentase penduduk dengan air bersih dan kemiskinan kabupaten/kota di sekitarnya.

\section{DAFTAR PUSTAKA}

Alvitiani S, Yasin H, dan Mukid MA. 2019. Pemodelan Data Kemiskinan Provinsi Jawa Tengah Menggunakan Fixed Effect Spatial Durbin Model. Jurnal Gausian vol 8 no 2. 220-232 
Anselin, L. 1988. Spatial Econometrics: Methods and Models, Kluwer Academic Publishers, The Netherlands.

Arbia, G. 2006. Spatial Econometrics: Statistical Foundations and Applications to Regional Convergence. Berlin: Springer.

Badan Pusat Statistik (2020), Provinsi Sumatera Barat dalam Angka 2020. Sumatera Barat: BPS Sumatera Barat.

Djuraidah A \& Wigena AH. 2012. Regresi Spasial untuk Menentukan Faktor-Faktor Kemiskinan di Provinsi Jawa Timur. Statistika vol 12 no 1. 1-8.

Fotheringham AS, Brunsdon C, Chartlon M. 2002. Geographically Weighted Regression, the analysis of spatially varying relationships. John Wiley and Sons. LTD.

Grasa AA. 1989. Econometric Model Selection: A New Approach, Kluwer.

Lee J \& Wong DWS. 2001. Statistical Analysis with Arcview GIS. John Willey and Sons Inc. New York.

LeSage JP.1999. The Theory and Practice of Spatial Econometrics, University of Toledo.

Medina J \& Solymosi R. (2019, 2 April). Chapter 9 Spatial Regression Models. [diakses pada 7 Januari 2021] dari: https://maczokni.github.io/crimemapping_textbook_bookdown/spatial-regressionmodels.html\#spatial-regimes

Schabenberger O \& Gotway CA. 2005. Statistical Methods for Spatial Data Analysis, Chapman \& Hall/CRC. 